\title{
Flight Testing of the Capillary Pumped Loop 3 Experiment
}

\author{
Laura Ottenstein ${ }^{1}$, Dan Butler ${ }^{1}$, Jentung Ku ${ }^{1}$, Kwok Cheung ${ }^{2}$, Robert Baldauff ${ }^{2}$, \\ and Triem Hoang ${ }^{3}$ \\ 'Thermal Engineering Branch, NASA/Goddard Space Flight Center, Greenbelt, MD 20771 \\ ${ }^{2}$ Naval Research Laboratory, Washington, DC, 20375 \\ ${ }^{3}$ TTH Research, Capitol Heights, MD 20743 \\ (301) 286-4141; laura.ottenstein@gsfc.nasa.gov
}

\begin{abstract}
The Capillary Pumped Loop 3 (CAPL 3) experiment was a multiple evaporator capillary pumped loop experiment that flew in the Space Shuttle payload bay in December 2001 (STS-108). The main objective of CAPL 3 was to demonstrate in micro-gravity a multiple evaporator capillary pumped loop system, capable of reliable start-up, reliable continuous operation, and heat load sharing, with hardware for a deployable radiator. Tests performed on orbit included start-ups, power cycles, low power tests (100 W total), high power tests (up to $1447 \mathrm{~W}$ total), heat load sharing, variable/fixed conductance transition tests, and saturation temperature change tests. The majority of the tests were completed successfully, although the experiment did exhibit an unexpected sensitivity to shuttle maneuvers. This paper describes the experiment, the tests performed during the mission, and the test results.
\end{abstract}

\section{INTRODUCTION}

The Capillary Pumped Loop 3 (CAPL 3) experiment consisted of a multi-evaporator capillary pumped loop (CPL) that flew in the Space Shuttle payload bay as part of the MACH 1 payload in December 2001 (STS-108). The experiment was a joint effort between the NASA's Goddard Space Flight Center (GSFC) and the Naval Research Laboratory (NRL), with Swales Aerospace as the industry partner. The experiment was a follow-on flight to the Capillary Pumped Loop (CAPL 1) and Capillary Pumped Loop 2 (CAPL 2) experiments, which were flown on the Space Shuttle on STS-60 (2/94) and STS-69 (9/95), respectively. The CAPL 1 experiment demonstrated a multievaporator CPL in space, but was only marginally successful, with significant start-up issues during the mission (Butler, Ottenstein and $\mathrm{Ku}, 1995$ ). The CAPL 2 experiment was entirely successful and demonstrated the operation of the two-phase thermal system that was subsequently used on NASA's Terra spacecraft (Ku, Ottenstein and Butler, 1996). The CAPL 2 capillary loop contained only one evaporator. For instruments with large footprints or several heat transfer zones, a CPL with multiple evaporators is needed. CAPL 3 demonstrated a multiple evaporator $\mathrm{CPL}$ with an advanced fluid management design that has a greater range of applications.

\section{EXPERIMENT DESCRIPTION}

The CAPL 3 experiment consisted of two physically separate assemblies - the CAPL 3 radiator assembly, and an electronics mounting plate holding the supporting experiment electronics. The CAPL 3 radiator assembly was mounted on an interface structure, which in turn was mounted on the top of the GAS Bridge Assembly (GBA) in the shuttle payload bay. The electronics mounting plate was attached to the side of the bridge, as shown in Figure 1. 


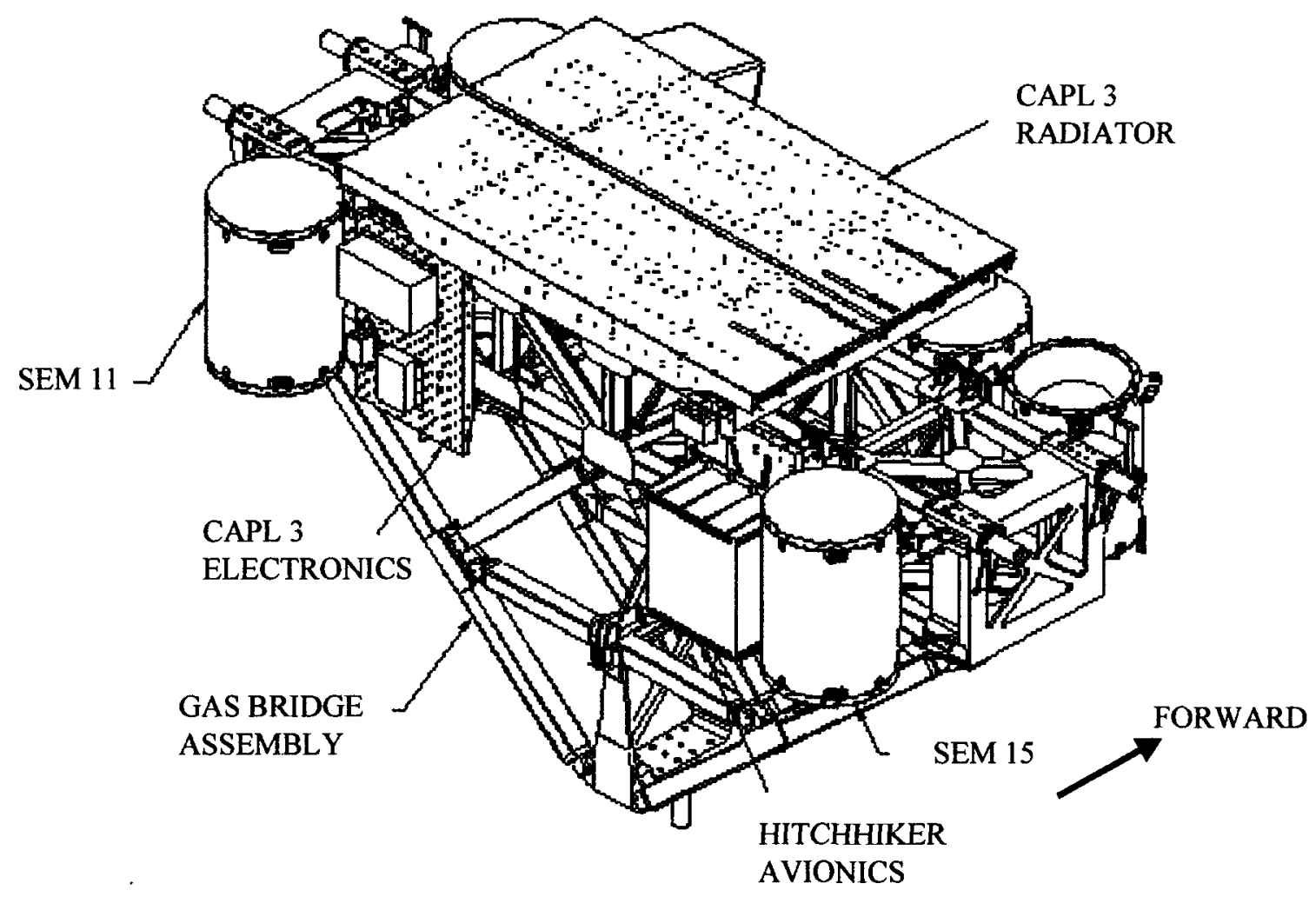

FIGURE 1. MACH 1 Payload Configuration.

The CAPL 3 radiator assembly housed the multi-evaporator CPL, which is shown schematically in Figure 2. The experiment structure and electronics were reflown from CAPL 1 and 2, but the CPL components were new for CAPL 3. The CPL contained a capillary starter pump and four capillary evaporators - two evaporators in one cold plate and two individual evaporators. Electrical resistance heaters mounted on the evaporators were used to simulate an instrument and to cause vaporization of the liquid ammonia. The vapor traveled to the condenser through stainless steel tubing. The vapor line contained a back-pressure regulator, which is a capillary device used to manage the fluid during the start-up process and during heat load sharing. The ammonia vapor was condensed via eight parallel direct-condensation tubes that were mounted to the radiator, and the liquid ammonia was returned to the evaporators by capillary pumping forces to complete the loop. The experiment was equipped with a reservoir that was used for temperature control of the saturated two-phase system under most conditions. The system was charged with anhydrous ammonia such that the CPL (except the reservoir) could be fully flooded with liquid ammonia prior to start-up of the system. One of the evaporators (Evaporator 3) was connected to a variable conductance heat pipe (VCHP), which in turn was connected to the radiator. This allowed the evaporator to act as a heat sink to demonstrate heat load sharing between the evaporators when needed. Instrumentation consisted of 180 thermistors, an absolute pressure transducer, and three differential pressure transducers, which monitored the pressure drop across the evaporator section, across the reservoir line, and across the back-pressure regulator in the vapor line. Heat rejection was accomplished via a radiator panel which measured $1.57 \mathrm{~m} \times 2.54 \mathrm{~m}$ (62 inches $\times 100$ inches). The experiment was operated real time during the mission from a control center located at GSFC.

\section{Evaporators}

The evaporators in CAPL 3 were $25.4 \mathrm{~mm}$ ( 1 inch) in diameter, and used ultra-high molecular weight polyethylene wicks and grooved external extrusions similar the evaporator on CAPL 2. The evaporators included design enhancements that were intended to make them more resistant to deprime (Ku, et al., 1998). The liquid returned to the evaporators through an internal bayonet, to aid in subcooling of the entire evaporator. In addition, there was a 
mesh structure in the core of each evaporator to manage any vapor bubbles present and keep them from entirely blocking the wick structure and thus depriming the evaporator.

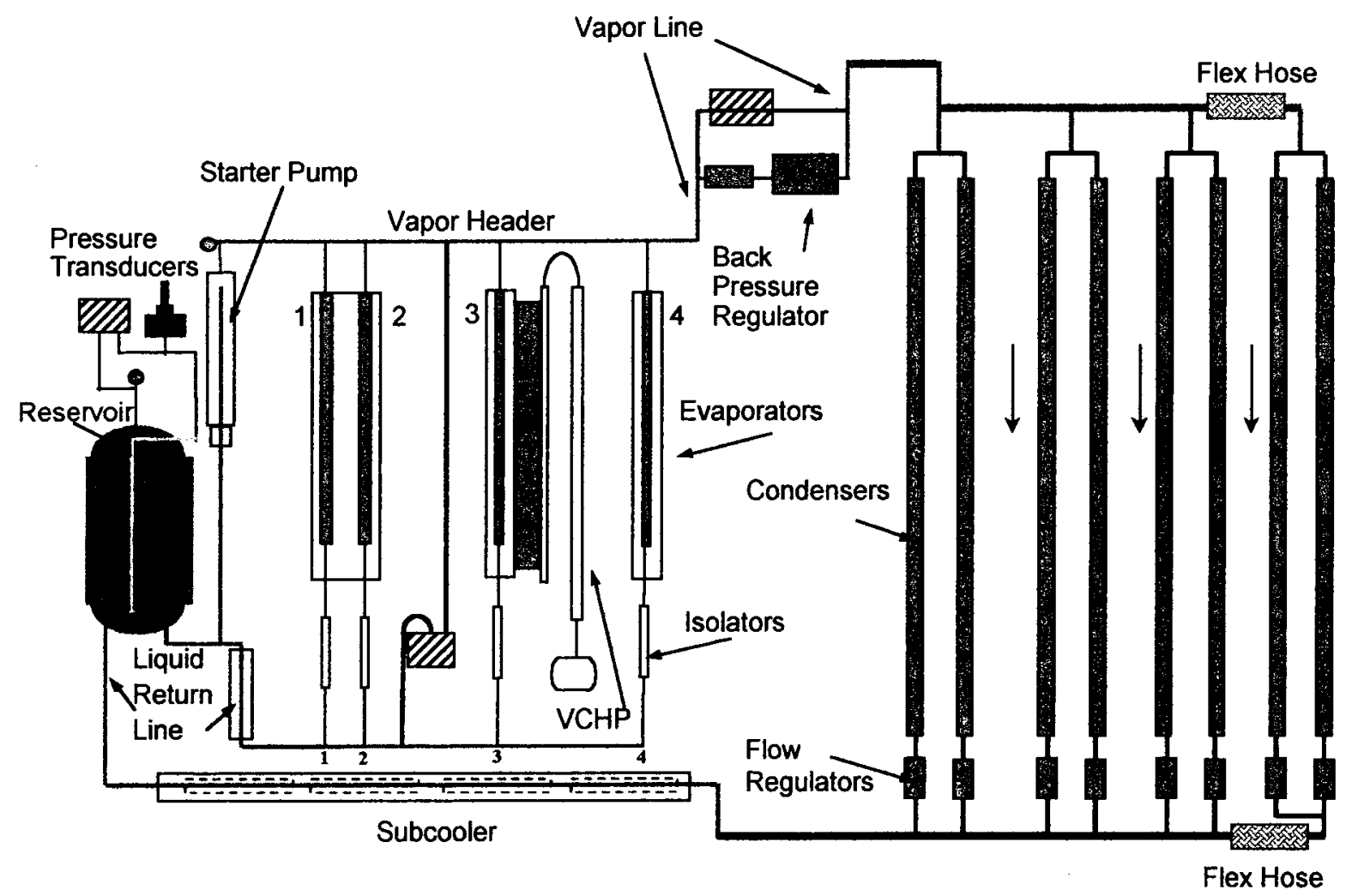

FIGURE 2. Capillary Pumped Loop Schematic.

\section{Reservoir}

The CAPL 3 reservoir was quite different from the reservoirs previously flown on CAPL 1 and CAPL 2. The internal walls of the reservoir were mostly covered by a polyethylene wick material to provide liquid to the heated zone and to the reservoir exit. An aluminum structure inside the reservoir provided the necessary wick seals. There was also a reservoir shroud located around the outside of the reservoir. The liquid return line was routed through this shroud to provide cooling to the reservoir. This design permits positive temperature control of the reservoir in all operating states, regardless of the reservoir location in the spacecraft (Ku, et al., 1998). The shroud to reservoir thermal coupling is primarily radiative, so that the liquid return maintains some subcooling even at low power conditions. Two electrical heaters $(28 \mathrm{~W}$ and $18 \mathrm{~W})$ were mounted to the outside of the reservoir to provide temperature control. In most cases, the two heater set points were set $0.5 \mathrm{C}$ apart, so that only one heater was used for fine temperature control.

\section{OBJECTIVES AND TEST PLAN}

The primary objective for the CAPL 3 experiment was to demonstrate in micro-gravity a multiple evaporator capillary pumped loop system, capable of reliable start-up, reliable continuous operation, and heat load sharing with hardware for a deployable radiator. In addition, goals included demonstrating heat transport of $1500 \mathrm{~W}$ in the system, demonstrating a single evaporator heat transport of $775 \mathrm{~W}$, and testing the ability of the system to transition to the fixed conductance mode of operation when the condenser was nearly fully utilized (Kim, et al., 1997). 
Planned tests were defined before the mission and run in both ambient and thermal vacuum conditions on the ground. The flight plan was divided into groups, or blocks, that generally began with a start-up procedure, and then continued to other tests until the shuttle allotted operating time was over. Tests were also prioritized so that the majority of the tests deemed more important were run early in the mission. However, attitude and power constraints required that high power tests be run later in the mission when the shuttle was in a colder attitude.

\section{Start-Up}

Start-up is often the most difficult operation performed with a CPL in that vapor can be generated in or pushed into the liquid core of the evaporator. This vapor bubble can either fail the evaporator immediately, or can grow over time to cause a deprime of the evaporator in subsequent tests (Butler, et al., 1995). Based on the results of the CAPL 1 and CAPL 2 experiments, and extensive ground tests, a start-up procedure was determined that is likely to assure continued operation of the system throughout the subsequent tests. The standard procedure was as follows: 1) Set reservoir temperature controller to desired set point (if not already there), and wait for at least 30 minutes after reservoir heater begins cycling. This step assures that the reservoir is the only place containing ammonia vapor, and that the rest of the system is fully flooded with liquid. 2) Apply $200 \mathrm{~W}$ to the starter pump and wait for the vapor line and all evaporator vapor grooves to be clear of liquid. The ammonia vapor generated by the starter pump travels down the vapor line until it reaches the back pressure regulator (BPR). The pressure difference required to force vapor through the capillary wick in the BPR is larger than the difference needed to clear the evaporator grooves of liquid, so vapor then flows into the evaporator vapor grooves until they are all clear of liquid. Once all the grooves are clear, the vapor blows through the BPR, since the pressure balance has shifted. 3) Apply 50 $W$ to each evaporator and wait for at least 30 minutes. Since the evaporator grooves are clear of liquid, the evaporators begin operating immediately. 4) Remove power from the starter heater and wait for at least 30 minutes. 5) Apply $150 \mathrm{~W}$ to each evaporator and wait for 30 minutes. 6) Reduce evaporator power back to $50 \mathrm{~W}$ per evaporator and wait for 30 minutes. If all four evaporators are operating at this point, the start-up is considered a success. The power cycle is included in the start-up procedure in order to quickly determine if there is a vapor bubble in an evaporator. Power cycling of an evaporator is one of several procedures that tend to cause a bubble in the core of the evaporator to grow. Since the system response to seemingly identical conditions can vary, the flight test plan included a number of start-up tests.

\section{High and Low Power Operation}

The amount of power that can be transported by a CPL is limited by the capillary pumping capability of the evaporator wicks and the pressure drop throughout the system. In practical terms, the high power limit is often higher than the actual heat dissipation of whatever the system is attached to. In this case, the maximum heater power available to the CPL was approximately $1500 \mathrm{~W}$ (375 W/evaporator), which was lower than the predicted heat transport capability. One evaporator was equipped with additional heaters in order to demonstrate a single evaporator heat transport capability of $775 \mathrm{~W}$. In each high power test, power was raised until the heater limit was reached. After 15 to 30 minutes at the maximum power, the power was lowered in steps back to a $100 \mathrm{~W}$ per evaporator.

Low power operation can be difficult with a CPL, because the slow flow rate of the returning liquid can lead to a loss of subcooling and the growth of a bubble in the evaporator core. As a result, the low power limit of a CPL is often a more important consideration in a system design than the high power limit. The smallest single heater on each evaporator for this experiment was $25 \mathrm{~W}$, and several tests were planned with long term operation at $25 \mathrm{~W}$ per evaporator.

\section{Stand-by Mode}

There are two possible approaches to thermal system operation when a satellite goes to safe-hold conditions. It is frequently desirable to stop the loop from operating in order to de-couple the instruments from the radiator and 
lower the survival heater requirements. However, in this application the desire was to maintain the CPL in an operational state during safe-hold conditions, so that a long start-up process would not be required once normal operation resumed. A test was therefore planned that simulated the changes that occur in a survival mode transition. In the procedure, the reservoir set point was lowered to $10^{\circ} \mathrm{C}$ and the evaporator power was lowered to $75 \mathrm{~W}$ each on evaporators 1 and 2 and removed entirely from evaporators 3 and 4 . This test had not been successful in ground tests, in that at least one evaporator deprimed during the transition to the colder reservoir temperature. However, it was decided to run the test during the flight for comparison.

\section{Variable/Constant Conductance Transition}

A CPL is typically a variable conductance heat transfer device. The heat conducted by the CPL will vary as the power into the system and the heat rejection temperature change, while the saturation temperature is held approximately constant. One consequence of this is that if more energy is put into the system than can be rejected by the system radiator, the CPL will suffer an abrupt failure. This is caused either by vapor returning the to evaporator in the liquid line, or by the increased system pressure drop that results from attempting to push vapor through all of the condenser flow regulators. In either case, the result is the presence of vapor in the core of the evaporator and an evaporator deprime. It is possible to design the CPL so that the system transitions to a fixed conductance mode of operation when the condenser is nearly fully utilized. At this point, the operating temperature of the loop rises until the thermodynamic conditions are such that all heat applied is rejected at the radiator. This transition is accomplished by charging the system with sufficient fluid so that once the condenser is open to a predetermined percentage (say $\mathbf{8 0 \%}$ ), the system reservoir is fully flooded with liquid. When the reservoir is fully flooded, control of the system saturation temperature automatically switches to the condenser and the temperature will change as necessary to reject the heat. CAPL 3 was charged such that it transitioned to fixed conductance mode when the condenser was $\mathbf{8 0 \%}$ open. Several tests were planned to verify that the system would transition to fixed conductance when necessary, and that it would transition back to variable conductance when possible.

\section{Heat Load Sharing}

One of the key advantages to using a multiple evaporator CPL for a thermal system is the ability to use the waste heat generated by an operating instrument to warm a non-operating instrument. The CAPL 3 experiment was designed to demonstrate this heat load sharing by using a variable conductance heat pipe to link one of the evaporators (number 3 ) directly to the radiator. During the heat load sharing test, the VCHP was activated and the heater power to evaporator 3 removed. The power to the remaining evaporators was gradually lowered until almost all vapor generated by the operating evaporators was being condensed in evaporator 3 . This represents an extreme situation, and was designed to test the limits of heat load sharing. In an actual system, part of the system vapor would be used to warm the non-operating components, but some heat would still be rejected by the loop radiator. When heat load sharing tests were not being performed, the VCHP was held off using a heater on its gas reservoir, to prevent a heat leak directly from the evaporator to the radiator.

\section{Variable Load Profiles}

Multiple evaporator CPL's can be used to maintain the temperature of a variety of instruments even as amount of energy being dissipated and the environmental conditions change. Several tests were planned to demonstrate that the system could continue to operate as the load distribution between the evaporators changed. In one test the power was varied among the evaporators between $300 \mathrm{~W}$ and $50 \mathrm{~W}$, in another the power was varied between $100 \mathrm{~W}$ and $0 \mathrm{~W}$, and in a third test, two of the evaporators were kept at $25 \mathrm{~W}$, one was held at $50 \mathrm{~W}$, and the last evaporator was at $\mathbf{0 W}$. In all cases, the various powers were rotated between the evaporators so that most or all combinations were tested. 


\section{TEST RESULTS}

The experiment flew on the Space Shuttle Endeavour (STS-108) from December 5 to December 17, 2001. The total operating time for CAPL 3 was more than 200 hours, with the longest single period of operation 58 hours. With the exception of a few repeats of high power tests, which could not be performed because the shuttle was power limited, all of the planned tests were performed. In addition, a number of modifications to test procedures based on flight results we also tested. Overall, the experiment was highly successful, and all desired operating conditions were demonstrated at least once.

\section{Start-Ups}

Nine start-up tests were performed during the mission and all were successful. Eight of the flight start-ups were performed following the standard procedure - seven at a saturation temperature of $30^{\circ} \mathrm{C}$ and one at $20^{\circ} \mathrm{C}$. The ninth start-up was performed at a saturation temperature of $5^{\circ} \mathrm{C}$ after the loop had been dormant under a very cold sink condition, and was performed with a starter pump power of $50 \mathrm{~W}$ and an evaporator power profile of $50 \mathrm{~W} / 100$ W/ $50 \mathrm{~W}$ per evaporator. This test was also successful, but took much longer to clear the vapor lines.

A typical start-up is shown in Figure 3. Approximately six minutes after the system started (at $0.88 \mathrm{hr}$ ), vapor reached the back pressure regulator. At this point, vapor began clearing the evaporator vapor grooves. The last evaporator to clear was evaporator 3 , due to the additional mass of the attached VCHP. Once evaporator 3 was fully cleared (at $1.5 \mathrm{hr}$ ), vapor quickly blew through the BPR and continued to the condenser. As this point, power was applied to the evaporators and they all began operating.

Superheat is often seen in the start-up of a fully flooded evaporator, and larger superheats are thought to indicate a more difficult start and a greater likelihood of vapor ending up in the evaporator core. Superheat in the starter pump temperatures during the mission was only seen in the $5^{\circ} \mathrm{C}$ and $20^{\circ} \mathrm{C}$ start-ups, not in the higher temperature startups. There was never any superheat in the other evaporator temperatures, which was expected since the vapor grooves were always clear of liquid before the evaporator power was applied.

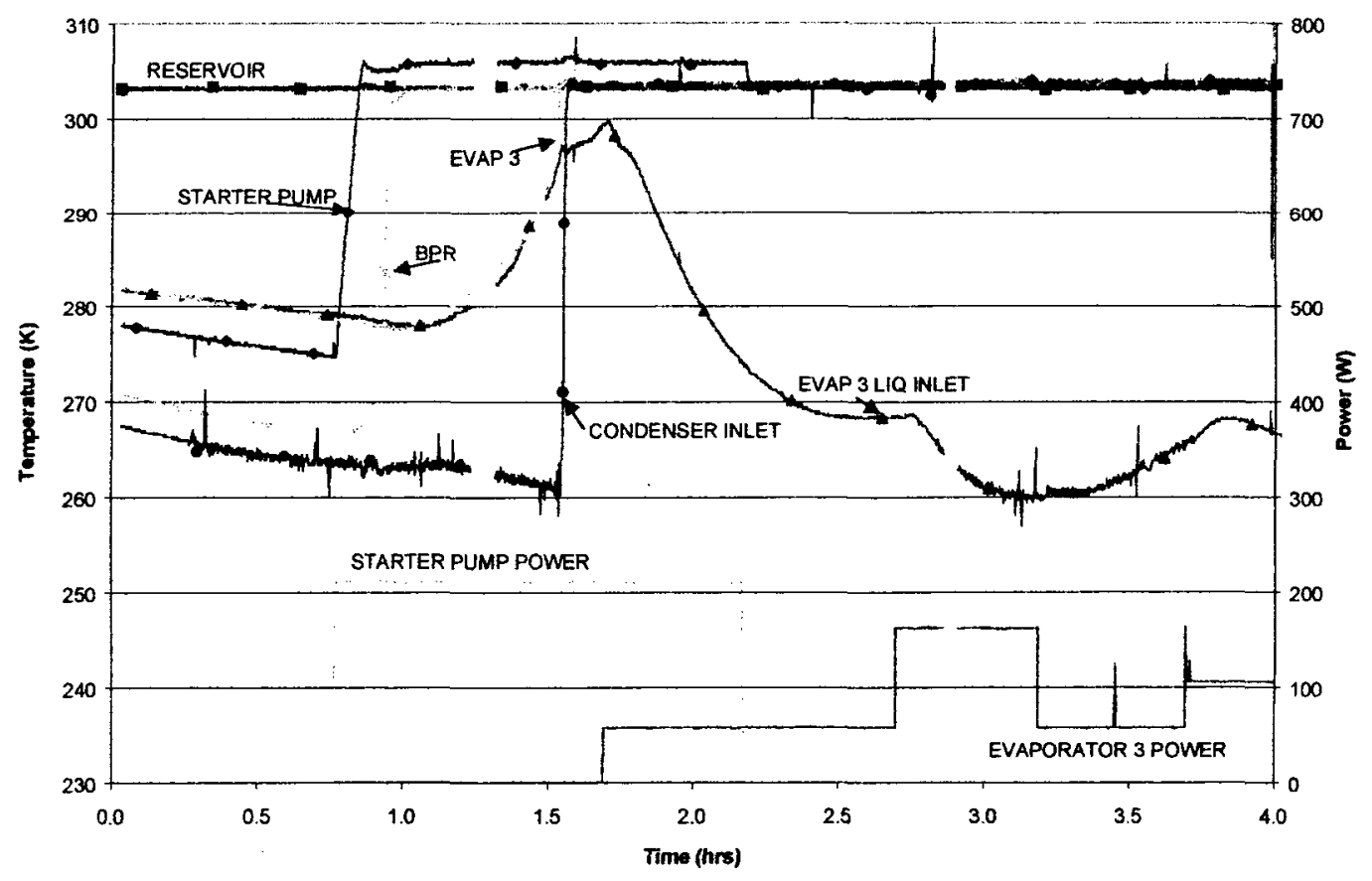

FIGURE 3. Start Up Test. 


\section{High and Low Power Operation}

Due to shuttle power limitations, the system high power test was only performed once. The highest power transported was $1447 \mathrm{~W}$ total, distributed evenly among the four evaporators, as shown in Figure 4. This figure shows that the evaporator temperature remains quite steady, even as the power is increased and the condenser temperatures change significantly. In a separate test, the highest single evaporator power was $756 \mathrm{~W}$. In each case, the test was limited by the heater capacity of the experiment, rather than the transport limit of the CPL.

Low power operation at $25 \mathrm{~W}$ per evaporator was demonstrated repeatedly during the mission. The longest single period at this power was seven hours. At the end of every low power period, the evaporator power was raised to 100 W per evaporator to show that the evaporators were still pumping.

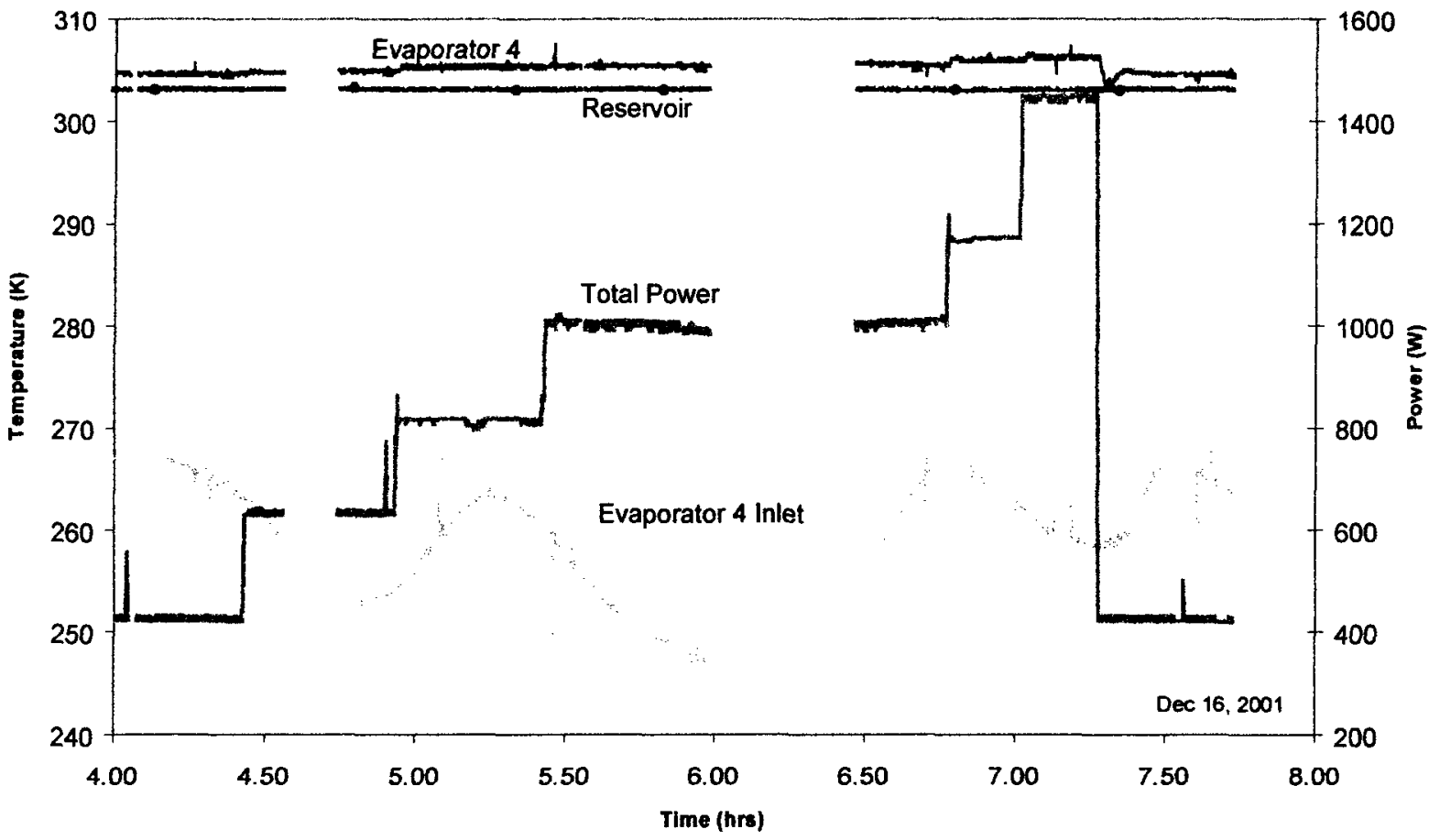

FIGURE 4. High Power Test.

\section{Stand-By Mode}

In the stand-by mode test, the saturation temperature was lowered from 303 to $283 \mathrm{~K}$ and at the same time, the power on evaporators 1 and 2 was lowered to $75 \mathrm{~W}$ each and the power was removed entirely from evaporators 3 and 4. Shortly after this transition, evaporator 3 deprimed, and a reprime and restart was required before the system was fully functional again. This result was similar to those seen in preflight ground testing. In this low power condition, the saturation temperature change occurred faster than the evaporators could respond. As a result, subcooling in the evaporators was lost and an evaporator deprimed. The test was subsequently repeated with the power change, but without the saturation temperature change (constant at $283 \mathrm{~K}$ ), and the system continued to operate normally throughout the stand-by period. The system was then returned to fully operational mode with the simple addition of power to evaporators 3 and 4. 


\section{Variable/Constant Conductance Transition}

Three tests of the variable/fixed conductance transition were attempted during the mission. One test could not be completed because the environment was too cold to utilize the condenser fully. Two tests were completed apparently successfully and demonstrated the transition from variable conductance operation to fixed conductance operation and back. However, in each case, an evaporator (always evaporator 4 ) deprimed in the subsequent test, and it is probable that this test contributed to those deprimes. Although the system was charged (in August 1999) to transition to fixed conductance when the condenser was $80 \%$ open, during the mission the transition occurred when the condenser was nearly $100 \%$ open, as shown in Figure 5. At this point the differential pressure across the evaporator $(>2750 \mathrm{~Pa})$ was higher than the capillary limit of the evaporator wicks, which probably resulted in vapor in the core of the evaporator pump. It appears that between the time of the final fluid charge and the flight, enough fluid (approximately 18 grams, out of a total charge of 1249 grams) leaked from the system to prevent the transition from occurring when it should have. In addition, the condenser and portions of the reservoir were colder than they had been in pre-flight testing. Since the density of the liquid goes up as the temperature decreases, this also lowers the volume occupied by the liquid. Due to the relatively small volume in the condensers, a small change in the fluid inventory can have a dramatic effect on the system operation in this case. Although this mode of operation was not entirely successfully, the basic mechanism was demonstrated, and a flight system would not be built with o-ring seals (like those in the differential pressure transducers), which have a tendency to leak slowly.

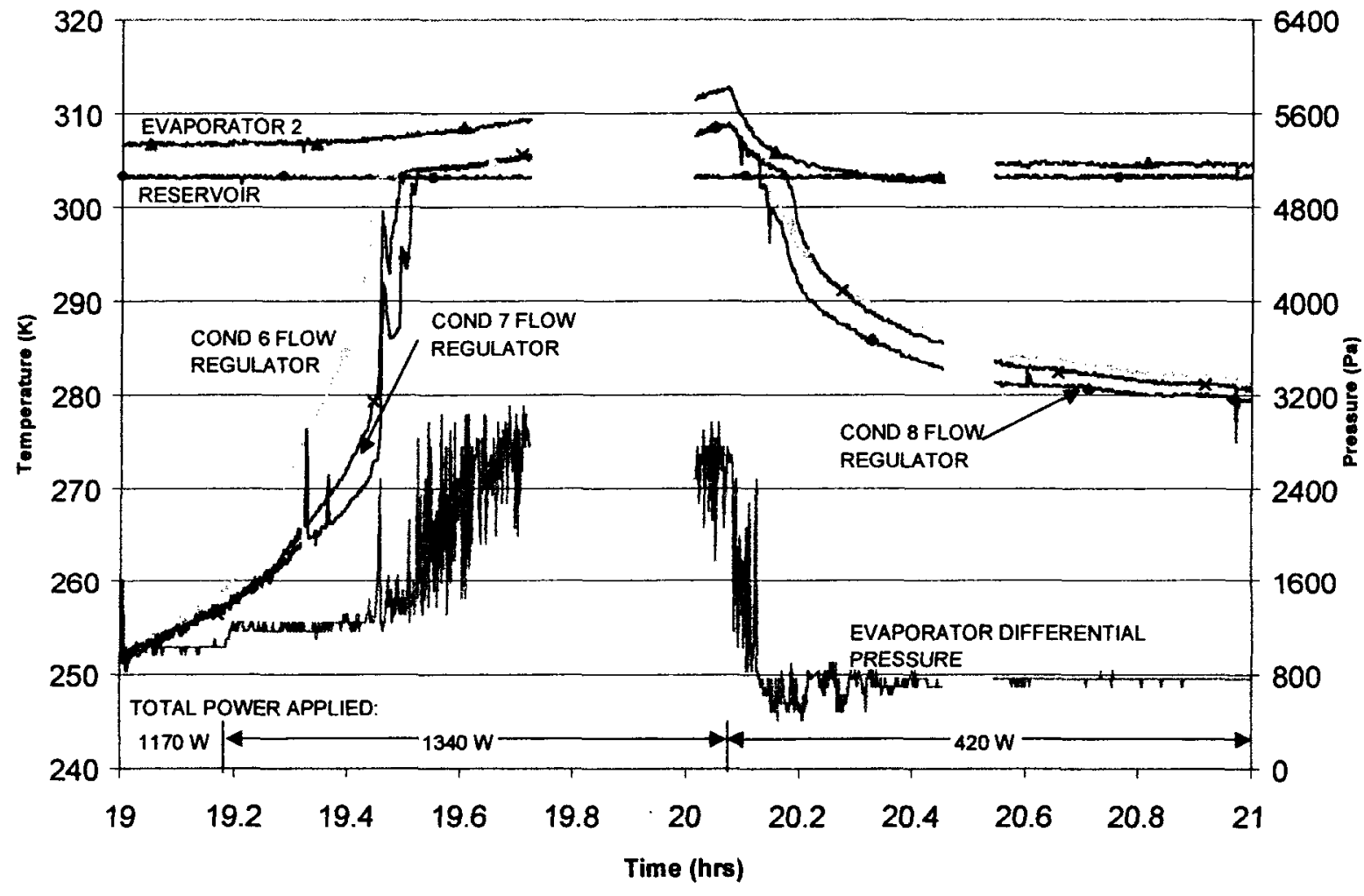

FIGURE 5. Variable/Constant Conductance Transition Test.

\section{Heat Load Sharing}

Six heat load sharing tests were run during the mission. In four of these tests, evaporator 4 deprimed during the test. A pre-existing bubble in the core of evaporator 4 may have contributed to these failures. Every test that ended in 
deprime followed a test that can be assumed to have resulted in a bubble in the evaporator core - two followed variable/fixed conductance tests, one followed a set point increase which repeatedly flooded and restarted the evaporators, and one test included several OMS burns during the procedure (see later section). As the percentage of the heat that is shared increases, the subcooling available to the operating pumps decreases, particularly to evaporators downstream of the heat load sharing evaporator. The very low subcooling available at low powers undoubtedly contributed to the failures seen during the heat load sharing tests. When the heat load sharing test was repeated with evaporator 4 kept at a higher power to maintain adequate subcooling and did not follow a bubble producing test, the test was completed successfully.

\section{Variable Load Profiles}

All of the variable load profiles tests during the mission were successful. Several of these tests demonstrated a more benign form of heat load sharing. One such test is shown in Figure 6. The power to the pumps was varied so that generally two pumps received $100 \mathrm{~W}$ and two pumps had no power applied. As can be seen in the figure, the pumps that did not have power applied remained at the saturation temperature during this power down period, and started immediately when power was reapplied. Note that since evaporators 1 and 2 were in a common cold plate, removing the power over one of them simply cut the power to the two evaporators in half and these two evaporators did not shut down. This type of operation is also similar to what would be required in an application where a CPL is used to isothermalize a large structure.

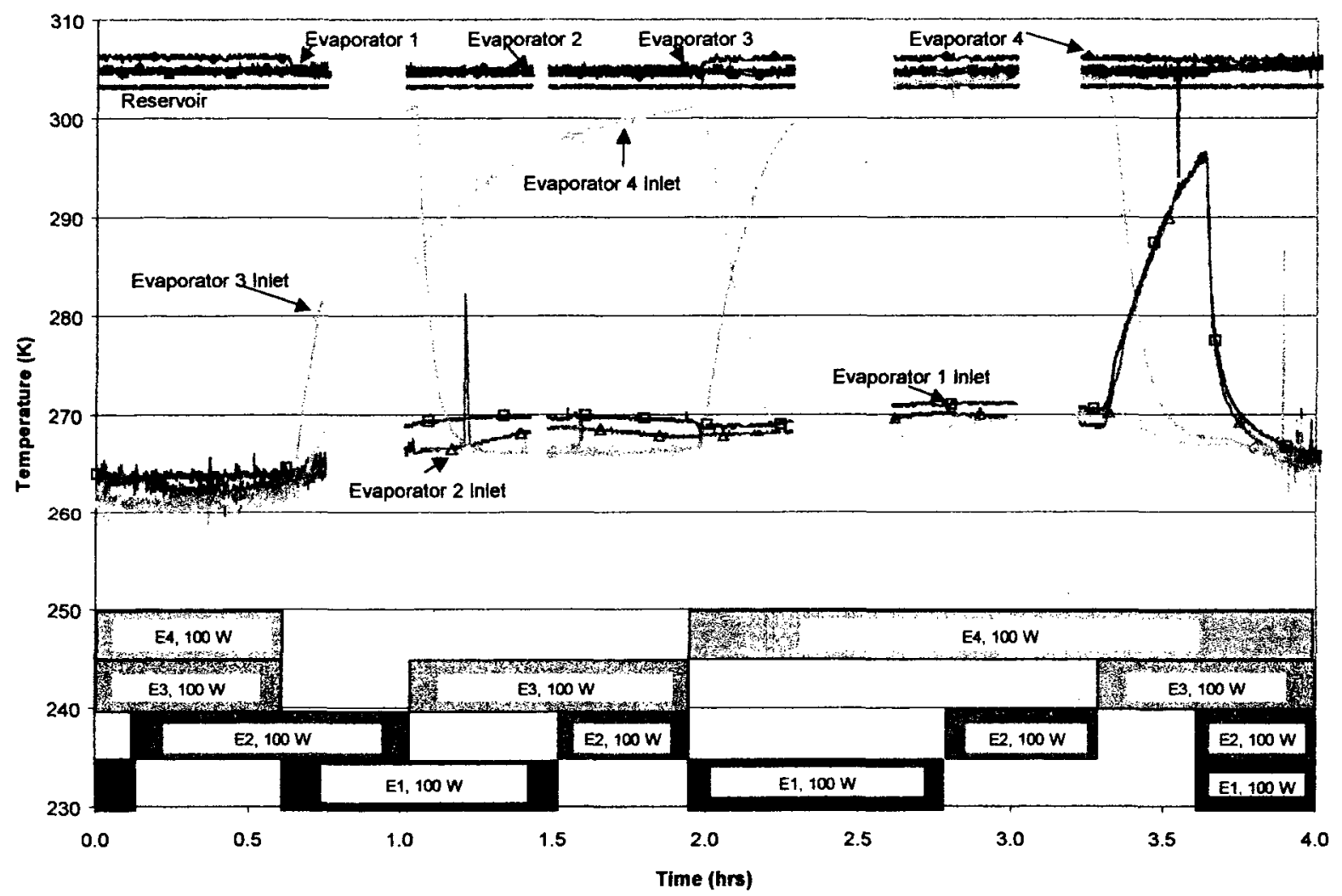

FIGURE 6. Variable Load Profile. 


\section{Reaction to Shuttle Maneuvers}

Since this was a flight to the space station, there were a significant number of shuttle maneuvers during the mission. Although the previous CAPL experiments had displayed some effects of shuttle maneuvers, this experiment showed a large reaction to shuttle maneuvers, particularly orbital maneuvering system (OMS) burns. The burns had the effect of shaking up the CPL reservoir and mixing the fluid inside. There were three instances during the mission when evaporator 4 deprimed immediately following a shuttle maneuver. Since the reservoir had a temperature gradient during normal operation of up to $14{ }^{\circ} \mathrm{C}$, mixing of this fluid rapidly lowered the CPL operating temperature. In one case the saturation temperature dropped $8{ }^{\circ} \mathrm{C}$ following an OMS burn. The deprimes occurred at relatively low power levels. When the evaporator was increased to $100 \mathrm{~W} /$ evaporator prior to the OMS burn, there was no deprime.

\section{CONCLUSIONS}

The purpose of the CAPL 3 experiment was to not only demonstrate a robust multi-evaporator CPL, but also to test the limits of this system. Although there were some deprimes when the system limits were crossed, as long as the tests performed stayed within known operating conditions, the CPL operation was entirely successful. The flight verified the following new technologies in micro-gravity: 1) cold biased reservoir using a reservoir shroud. 2) use of a starter pump and back pressure regulator for start-up of a multiple evaporator CPL, 3) parallel direct condensation condenser tubes with individual flow regulators, and, 4) advanced evaporators with bubble management features. This experiment also demonstrated that variable/fixed conductance transitions and near $100 \%$ heat load sharing are feasible, but that their use in an application may require design changes to guarantee long term reliability.

\section{ACKNOWLEDGMENTS}

Special thanks to Swales Aerospace, the CAPL 3 industrial partner. Sponsorship for this experiment was received from the Naval Research Laboratory, NASA's Earth Science Technology Office, and NASA's Code Y (Earth Science).

\section{REFERENCES}

Butler, D., Ottenstein, L., and Ku, J., "Flight Testing of the Capillary Pumped Loop Flight Experiment," Paper No. 951566, presented at $25^{\text {th }}$ International Conference on Environmental Systems, San Diego, California, July 10-13, 1995.

Kim, J, et al., "The Capillary Pumped Loop III (CAPL 3) Flight Demonstration Description and Status," in the proceedings of Space Technology and Applications International Forum (STAIF-1997), edited by M. El-Genk, AIP Conference Proceedings 387, Melville, NY, 1997, pp. 623-628.

Ku, J., Ottenstein, L., and Butler, D., "Performance of the CAPL 2 Flight Experiment," Paper No. 961432, presented at 26" International Conference on Environmental Systems, Monterey, California, July 8 - 11, 1996.

Ku, J., Ottenstein, L., Cheung, K., Hoang, T., and Yun, S.J., "Ground Tests of Capillary Pumped Loop 3 (CAPL 3) Flight Experiment," Paper No. 981812, presented at the $28^{\text {th }}$ Intemational Conference on Environmental Systems, Danvers, Massachusetts, July 13-16, 1998. 